\title{
DIVISION XII / COMMISSION 41 / WORKING GROUP HISTORICAL INSTRUMENTS
}

\author{
CHAIR \\ PAST CHAIR \\ MEMBERS
}

\author{
Luisa Pigatto \\ Nha Il-Seong \\ Jürgen Hamel, Kevin Johnson, \\ Rajesh Kochhar, Tsuko Nakamura, \\ Nha Il-Seong, Wayne Orchiston, \\ Bjrn R. Pettersen, Sara J. Schechner, \\ Shi Yunli
}

\section{PROCEEDINGS BUSINESS MEETING on 23 August 2006}

\section{Introduction}

The Working Group Historical Instruments (WG-HI) was founded by the members of Commission 41 at the 2000 Manchester IAU XXIV General Assembly, with the main objectives to assemble a bibliography of existing publications relating to such instruments, and to encourage colleagues to carry out research and publish their results. Membership of the WG-HI has increased from three to nine people since its foundation. This clearly demonstrates the IAU members increasing interest in safeguarding old astronomical instruments and buildings as witness to their own country's cultural heritage and scientific progress.

\section{The WG's scientific sessions at Prague IAU GA}

The WG-HI held three sessions in Prague, on Wednesday, August 23: the first was devoted to WG business and the last two, to oral and poster papers presentation. The scientific topic focused on the theme The world-wide search for historically significant astronomical instruments. The agenda and presentations for these latter two sessions are available on the WG-HI website.

\section{The thesaurus of historical instruments}

An important task of the WG-HI is to prepare a Thesaurus of historical instruments used in astronomy and related disciplines such as geography, geodesy, navigation, meteorology and chronology. The Thesaurus is a controlled and structured list of terms defining instruments for observations and measurements in a very precise way. Historical instruments will be defined on the basis of the first printed sources describing the instruments themselves. Identifying correctly old instruments gives an additional useful tool to study and preserve the heritage testifying the progress of astronomy during the centuries.

\section{WG Historical Instruments website}

From 2006 Prague GA, Luisa Pigatto, has taken the task of making, developing and maintaining the WG-HI website. Presentations and Abstracts at the WGs scientific sessions in Prague as well as members reports, are there available in pdf format. Links to Science Museums and historical instruments collections websites are also given. A list of printed books related to astronomy, geography, geodesy, navigation, meteorology and chronology in which instruments and their use are described, is in progress. 


\section{Closing remarks}

The International Year of Astronomy 2009 (IYA2009) commemorates the 400th anniversary of Galileos telescope, the main instrument in the history of astronomy. The WG-HI is particularly involved in planning events related to historical instruments, their use and improvement on which the progress in astronomy is based.

Luisa Pigatto chair of the Working Group 